Research Article

\title{
Genetic Background of Antimicrobial Resistance in Multiantimicrobial-Resistant Escherichia coli Isolates from Feces of Healthy Broiler Chickens in Tunisia
}

\author{
Mohamed Salah Abbassi $\left(\mathbb{D},{ }^{1,2}\right.$ Hajer Kilani, ${ }^{1,2}$ Islem Abid, ${ }^{3}$ Yolanda Sáenz ${ }^{\mathbb{D}},{ }^{4}$ Paul Hynds, ${ }^{5}$ \\ Sana Lengliz $\mathbb{1},{ }^{1}$ Noureddine Ben Chehida, ${ }^{1}$ and Ilhem Boutiba-Ben Boubaker ${ }^{2}$ \\ ${ }^{1}$ Université de Tunis El Manar, Institut de la Recherche Vétérinaire de Tunisie, 20 Rue Jebel Lakhdhar, Bab Saadoun, \\ Tunis 1006, Tunisia \\ ${ }^{2}$ Université de Tunis El Manar, Faculté de Médecine de Tunis, Laboratoire de Résistance Aux Antibiotiques LR99ES09, Tunisia \\ ${ }^{3}$ Department of Botany and Microbiology, College of Science, King Saud University, Riyadh 11451, Saudi Arabia \\ ${ }^{4}$ Área de Microbiología Molecular, Centro de Investigación Biomédica de La Rioja (CIBIR), Logroño, Spain \\ ${ }^{5}$ Environmental Sustainability and Health Institute (ESHI), Technological University Dublin, Grangegorman, Dublin 7 , \\ Dublin, Ireland \\ Correspondence should be addressed to Mohamed Salah Abbassi; salahtoumi_mohamed@yahoo.com
}

Received 8 May 2021; Revised 10 July 2021; Accepted 12 September 2021; Published 1 October 2021

Academic Editor: Fazul Nabi

Copyright (C) 2021 Mohamed Salah Abbassi et al. This is an open access article distributed under the Creative Commons Attribution License, which permits unrestricted use, distribution, and reproduction in any medium, provided the original work is properly cited.

\begin{abstract}
Multiantimicrobial-resistant Escherichia coli isolates are a global human health problem causing increasing morbidity and mortality. Genes encoding antimicrobial resistance are mainly harbored on mobile genetic elements (MGEs) such as transposons and plasmids as well as integrons, which enhance their rapid spread. The aim of this study was to characterize 83 multiantimicrobial-resistant E. coli isolates recovered from healthy broiler chickens. Among 78 tetracyclineresistant isolates, the tet $A$, tet $B$, and tet $C$ genes were detected in 59 (75.6\%), 14 (17.9\%), and one (1.2\%) isolates, respectively. The sul1, sul2, and sul3 genes were detected 31 (46.2\%), 16 (23.8\%), and 6 (8.9\%) isolates, respectively, among 67 sulfonamide-resistant isolates. The PCR-based replicon typing method showed plasmids in 29 isolates, IncFIB (19), IncI1-I $\gamma$ (17), IncF (14), IncK (14), IncFIC (10), IncP (8), IncY (3), IncHI2 (1), and IncX (1). The class 1 and 2 integrons were detected in 57 and 2 isolates, respectively; one isolate harbored both integrons. Seven and one gene cassette arrays were identified in class 1 and class 2 integrons, respectively. Our findings show that multiantimicrobial-resistant E. coli isolates from chickens serve as reservoirs of highly diverse and abundant tet and sul genes and plasmid replicons. Such isolates and MGEs pose a potential health threat to the public and animal farming.
\end{abstract}

\section{Introduction}

Escherichia coli is a normal part of the microbiota of the lower gastrointestinal tract of warm-blooded animals and humans and usually exists as a harmless commensal. However, there also exist many pathogenic strains of $E$. coli that can cause a variety of diarrheal and other extraintestinal infections in humans and animals. The emergence of $E$. coli isolates with multiple antibiotic resistance phenotypes has been previously reported and is considered a serious health concern $[1,2]$. In Enterobacteriaceae and particularly in E. coli, resistance to beta-lactams due to extended spectrum beta-lactamases (ESBL), quinolones, and aminoglycosides has drawn considerable attention worldwide [3]. ESBLproducing isolates are usually resistant to other antimicrobial agents such as aminoglycosides, tetracyclines, chloramphenicol, trimethoprim, sulfonamides, or quinolones, often due to the presence of multiple resistance genes on transferable genetic elements such as plasmids, transposons, or integrons [4-8]. In the last decade, it has been observed that 
ESBL producers and multiantimicrobial-resistant E. coli isolates are frequently detected in food-producing animals or food products; therefore, health authorities are worried about the potential transmission of these resistant microorganisms to humans through the food chain $[2,3,9]$. Likewise, in Tunisia, many reports have highlighted high rates of antimicrobial resistance and ESBL production in E. coli isolates from foodproducing animals or food products [9-12], a situation that requires more investigations and vigilance to reduce large dissemination of such resistant isolates.

Mobile genetic elements such as plasmids, transposons, and integrons are able to disseminate genes encoding antibiotic resistance by horizontal transfer and play an important role in the evolution and dissemination of multiantimicrobial resistance in Gram-negative bacteria [13]. Five classes of integrons related to antimicrobial resistance have been described based on the homology of their integrase genes [14]. However, class 1 and 2 were the most prevalent integrons in Enterobacteriaceae. Class 1 integron comprises two conserved segments, the $5^{\prime}$ conserved sequence $\left(5^{\prime} \mathrm{CS}\right)$ (bearing int 1 gene) and the $3^{\prime}$ conserved sequence $\left(3^{\prime} \mathrm{CS}\right)$ (containing qacEA-sul1 genes) and an internal variable region $[5,13,14]$. Variable regions are able to contain many gene cassettes, which might explain, in part, the multiantimicrobial resistance trait of some reported isolates [13, 14].

In Tunisia, little is known about the epidemiology of antimicrobial resistance in Enterobacteriaceae, especially in E. coli, of animal origin. However, recent studies highlighted high rates of antimicrobial-resistant $E$. coli isolates from avian farms [9-11]. Therefore, in this work, we aimed to study 83 multiantimicrobial-resistant $E$. coli isolates recovered from healthy broiler chickens by determining genes encoding tetracycline and sulfonamide resistance and the occurrence of integrons and plasmid types. This study will allow us to better understand the genetic background of antimicrobial resistance in these isolates.

\section{Materials and Methods}

2.1. Bacterial Strains and Epidemiological Background. A program of regular surveillance of antimicrobial resistance in zoonotic bacteria of animal origin has been established at 2009 by the laboratory of bacteriological research in the Tunisian Institute of Veterinary Research, Tunisia. According to this program, samples (feces, milk, meat, and organs) from various animals (healthy or sick) have been collected and analyzed to study antimicrobial susceptibilities of pathogenic strains or indicator species such as Enterococcus spp. and E. coli. Between June 2009 and December 2015, one hundred seventy fresh feces samples of healthy broiler chickens were collected from 8 unrelated intensive farms (each with 2000-5000 animals) in Siliana $(n=20)$, El-Kef $(n=20)$, Sidi Bouzid $(n=20)$, Beja (20), Nabeul (25), Bousalem $(n=20)$, Mateur $(n=20)$, and Sousse $(n=25)$ regions, Tunisia. The mean average age of the broilers was 38 days. The farms were selected by considering their geographical location and the size of the farms (at least 2000 chickens per farm). A single fecal dropping from each chicken was collected with sterile swab. Following sample collection, the samples were transported immediately to the laboratory in an insulating foam box with ice and were analyzed within $24 \mathrm{~h}$. Five grams of feces was incubated in $5 \mathrm{~mL}$ of Brain Heart Infusion (BHI, Becton Dickinson) for $1 \mathrm{~h}$ at $37^{\circ} \mathrm{C}$. After serial dilutions, $100 \mu \mathrm{L}$ of the suspension was streaked onto MacConkey Agar (MSA, Becton Dickinson) and incubated at $37^{\circ} \mathrm{C}$ for $18-24 \mathrm{~h}$. One colony with typical E. coli trait from each sample was picked and reisolated on MacConkey's agar. Isolates were preidentified by Gram staining and classical biochemical (tests of oxidase, urease, indole, and growth on simmonse citrate) and then confirmed by biochemical identification using Api20E (Bio-Mérieux, France).

2.2. Antimicrobial Susceptibility Testing. Antimicrobial susceptibility testing was carried out by the agar disk diffusion method on Mueller-Hinton agar plates according to therecommendation of Clinical and Laboratory Standards Institute guidelines [15]. The tested antimicrobial agents were amoxicillin $(25 \mu \mathrm{g})$, ticarcillin $(75 \mu \mathrm{g})$, imipenem $(10 \mu \mathrm{g})$, nalidixic acid $(30 \mu \mathrm{g})$, ciprofloxacin $(5 \mu \mathrm{g})$, sulfonamide $(300 \mu \mathrm{g})$, trimethoprim/sulfamethoxazole $(1.25 / 23.75 \mu \mathrm{g})$, tetracycline $(30 \mu \mathrm{g})$, gentamicin $(10 \mu \mathrm{g})$, kanamycin $(30)$, streptomycin $(10 \mu \mathrm{g})$, and chloramphenicol $(30 \mu \mathrm{g})$. For all isolates, the double-disk synergy test (DDST) with cefotaxime or ceftazidime in the proximity to amoxicillinclavulanic acid was used for the screening of ESBL [15]. E. coli ATCC25922 was used as ESBL negative, and Klebsiella pneumoniae 700603 was used as a ESBL-positive reference strain. Isolates demonstrating intermediate susceptibility or resistance to three or more classes of antimicrobial agents were classified as multidrug-resistant (MDR) [16] and were further characterized in this study.

2.3. Genomic DNA Extraction. Genomic DNA was extracted from each isolate using the boiling method. Briefly, a loopful of cell bacteria from an overnight culture on Mueller-Hinton Agar (Bio-Rad) was suspended in Eppendorf tube containing $500 \mu \mathrm{L}$ of DNase-RNase-free distilled water. The Eppendorf tube was incubated for $15 \mathrm{~min}$ at $100^{\circ} \mathrm{C}$ and placed immediately at $-20^{\circ} \mathrm{C}$ for $10 \mathrm{~min}$. The tube was centrifuged for $5 \mathrm{~min}$ at $10,000 \times \mathrm{g}$ at $4^{\circ} \mathrm{C}$. The supernatant containing genomic DNA was stored at $-20^{\circ} \mathrm{C}$ until use for PCR experiments.

2.4. Plasmid Typing. Plasmids were typed according to their incompatibility group (18 Inc groups) using the PCR-based replicon typing method [17].

2.5. Detection and Characterization of Class 1 and 2 Integrons. Class 1 and 2 integrons and the $3^{\prime}$ conserved sequence $\left(3^{\prime} \mathrm{CS}\right)$ (qacEA-sul1) of class 1 integrons were amplified by PCR as previously reported [18]. In addition, the variable regions (VR) of class 1 and 2 the integrons were amplified and sequenced in 20 randomly selected class 1positive isolates (one of them contained also class 2) and one class 2-positive isolate [18]. Amplicons of variable regions were purified through K501 spin columns Biomatik (Wilmington, DE) and were sequenced using appropriate primers, the AmpliTaq DNA polymerase FS Dye Terminator Cycle Sequencing Ready Reaction kit (Applied Biosystems, 
Courtaboeuf, France) and the automatic ABI Prism_3100 genetic analyzer (Applied Biosystems). The sequences were confirmed with those in the GenBank nucleotide database using the basic local alignment search tool (BLAST) program available through the National Center for Biotechnology Information website (http://www.ncbi.nlm.nih.gov/BLAST). For nonclassical class 1 integrons, VR were determined by the primer walking strategy [18].

2.6. Detection of the Genes Encoding Tetracycline and Sulfonamide Resistance and ESBL Production. The presence of genes encoding tetracycline $(\operatorname{tet} A, \operatorname{tet} B$, and $\operatorname{tet} C)$ and sulfonamide resistance (sul1, sul2, and sul3) was investigated by PCR for all resistant isolates to these markers as reported previously [18]. The presence of $b l a_{\mathrm{TEM}}, b l a_{\mathrm{SHV}}$, and $b l a_{\mathrm{CTX}-\mathrm{M}}$ genes associated to the production of ESBL was investigated by PCR with specific primers as previously described [12]. bla amplicons were purified and sequenced on both strands using appropriate primers as mentioned above. The nucleotide and their deduced amino acid sequences were compared with those included in the GenBank database using the BLAST tool of the National Center for Biotechnology Information website (http://www.ncbi.nlm.nih.gov/BLAST).

2.7. Statistical Analysis. Statistical analysis was performed by means of Pearson's chi-square test (with Yate's correction) to check if there were differences among integron-positive and integron-negative isolates in relation with antimicrobial resistance phenotypes and presence of sul and tet gene types.

\section{Results}

3.1. Susceptibility to Antibiotics. All the 170 fecal samples contained typical colonies of $E$. coli. One colony per sample was randomly selected, confirmed as E. coli par Api20E and tested for its susceptibility to antimicrobial agents. According to their antimicrobial susceptibility, among the $170 \mathrm{E}$. coli isolates, 83 (48.8\%) were classified as multiantimicrobial resistant and were further characterized in this study. Among the 83 isolates, high rates of resistance were observed for tetracycline (78 isolates, $93.9 \%$ ), sulfonamides (67 isolates, $80.7 \%$ ), streptomycin (62 isolates, $74.6 \%$ ), amoxicillin (55 isolates, 66.2\%), nalidixic acid (46 isolates, 55.4\%), and amoxicillin/clavulanic acid (36 isolates, 43.3\%). Moderate frequencies of antimicrobial resistance were noted for ciprofloxacin and ticarcillin (each 27 isolates, 32.5\%). Low frequencies were observed for kanamycin (7 isolates, 8.4\%), cefotaxime (3 isolates, 3.6\%), and ceftazidime ( 2 isolates, $2.4 \%)$. Interestingly only one ESBL-producing E. coli isolate was detected. Resistance to imipenem, gentamicin, and chloramphenicol were not detected.

3.2. Genes Encoding Tetracycline and Sulfonamide Resistance and ESBL Production. The tet $A, \operatorname{tet} B$, and tetC genes were observed in 59 (75.6\%), 14 (17.9\%), and one (1.2\%) tetracycline-resistant isolates, respectively. tet $A$ and tet $B$ genes were simultaneously found in 6 isolates. Sixty-seven isolates were sulfonamide resistant, and sul-type genes were detected in $44(67.6 \%)$ of them. The sul1, sul2, and sul3 genes were detected in 31 (46.2\%), 16 (23.8\%), and $6(8.9 \%)$ resis- tant isolates, respectively. The combinations of following genes were identified (number of isolates): sul1+sul2 (4), sull+sul3 (3), sul2+sul3 (1), and sul1+sul2+sul3 (1). It is interesting to note that isolates containing integrons were more resistant to different antimicrobial families than integron-free isolates (Tables 1 and 2). As shown in Table 2, $51.7 \%(n=30)$ of integron-positive isolates showed resistance to at least five different antimicrobial families versus $24 \%$ $(n=6)$ of integron-negative isolates (statistically significant, $p<0.001)$.

It is also worth noting that we showed a positive correlation between the presence of integrons and the detection of genes encoding resistance to tetracycline and to sulfonamides (Table 3). Indeed out of 44 isolates harboring sultype genes, $37(84 \%)$ were integron positive $(p<0.001)$. Similarly, among 68 tet gene-positive isolates, $46(67.6 \%)$ were integron positive $(p<0.001)$. The ESBL producer isolate was class 1 integron positive and contained the $b l a_{\mathrm{CTX-M-1}}$, tet $\mathrm{B}$, and sul1 genes.

3.3. Plasmid Incompatibility Groups. PCR was used to identify incompatibility plasmid groups (or plasmid replicon types) by using genomic DNA of the 83 multiantimicrobialresistant E. coli isolates. Twenty-nine (34.9\%) isolates carried at least one incompatibility plasmid group, including (number of isolates) IncFIB (19), IncI1-I $\gamma$ (17), IncF (14), K (14), IncFIC (10), IncP (8), Y (3), IncHI2 (1), and IncX (1). Interestingly, $22(26.5 \%)$ isolates harbored at least two plasmid replicon types and various combinations were detected (number of isolates): $\mathrm{FIB}+\mathrm{F}+\mathrm{I} 1-\mathrm{I} \gamma(3), \mathrm{FIB}+\mathrm{F}+\mathrm{K}+\mathrm{Y}(2), \mathrm{F}+$ $\mathrm{K}+\mathrm{I} 1-\mathrm{I} \gamma(2), \mathrm{FIB}+\mathrm{FIC}+\mathrm{K}+\mathrm{I} 1-\mathrm{I} \gamma(1), \mathrm{FIB}+\mathrm{F}+\mathrm{K}+\mathrm{P}(1), \mathrm{FIB}+\mathrm{F}+$ $\mathrm{FIC}+\mathrm{K}+\mathrm{P}(1), \mathrm{FIB}+\mathrm{K}+\mathrm{P}(1), \mathrm{FIB}+\mathrm{K}+\mathrm{P}+\mathrm{HI} 2(1), \mathrm{FIC}+\mathrm{K}+\mathrm{Y}$ (1), $\mathrm{FIB}+\mathrm{K}+\mathrm{Y}+\mathrm{I} 1-\mathrm{I} \gamma(1), \mathrm{FIB}+\mathrm{F}+\mathrm{K}+\mathrm{I} 1-\mathrm{I} \gamma \quad(1), \mathrm{FIB}+\mathrm{F}+\mathrm{P}+\mathrm{I} 1-$ $\mathrm{I} \gamma(1), \mathrm{I} 1-\mathrm{I} \gamma+\mathrm{FIB}(1), \mathrm{FIB}+\mathrm{F}+\mathrm{X}+\mathrm{I} 1-\mathrm{I} \gamma(1), \mathrm{FIB}+\mathrm{F}+\mathrm{FIC}+\mathrm{Y}+\mathrm{I} 1-$ $\mathrm{I} \gamma(1), \mathrm{FIB}+\mathrm{F}+\mathrm{FIC}+\mathrm{K}(1), \mathrm{FIB}+\mathrm{F}+\mathrm{FIC}+\mathrm{I} 1-\mathrm{I} \gamma+\mathrm{K}(1)$, and FIB+ $\mathrm{K}(1)$.

3.4. Occurrence of Integrons and Variable Regions. Class 1 and 2 integrons were detected in 58 isolates. Fifty-seven isolates harbored the class 1 integrons, while class 2 was found only in two isolates. One isolate harbored both integrons. The $3^{\prime} \mathrm{CS}$, mainly present in the typical class 1 integron, was detected in twenty-two isolates (38.5\%) among 57 class 1 integron positive. The variable regions of class 2 integrons in the two isolates presented the same gene cassette array: dfrA1-sat1-aadA1. For the VR of class 1 integrons, seven arrangements of gene cassettes were found containing different alleles of $d f r A$ (resistance in the trimethoprim), aadA (resistance in the streptomycin), and $\mathrm{cmlA}$ (resistance to chloramphenicol). These arrangements were as follows (number of isolates): $d f r A 1$-aadA1 (10), dfrA12-orfF-aadA2 (3), dfrA5 (1),dfrA17-aadA5 (2), aadA1 (1),dfrA1 (1), and dfrA12-orfF-aadA2-cmlA1-aadA1-qacH-IS440-sul3

(Figure 1).

\section{Discussion}

Among the 83 multiantimicrobial-resistant isolates, tetracycline resistance was observed in 78 isolates (93.9\%). Indeed, 
TABle 1: Percentages of resistant isolates among the 83 E. coli to the tested antimicrobial agents in relation with the presence or absence of integrons.

\begin{tabular}{|c|c|c|c|}
\hline Antimicrobial agents ( $n$ of resistant isolates) & Resistance frequencies (\%) & $\begin{array}{c}\text { Integron positive (58 isolates) } \\
N(\%)\end{array}$ & $\begin{array}{l}\text { Integron negative (25 isolates) } \\
\qquad N(\%)\end{array}$ \\
\hline Streptomycin (62) & 74.6 & $45(72.5)$ & $17(27.4)$ \\
\hline Kanamycin (7) & 8.4 & $6(85.7)$ & $1(14.2)$ \\
\hline Gentamicin $(0)$ & 0 & na & na \\
\hline Tetracycline $(78)$ & 93.9 & $59(75.6)$ & $19(24.3)$ \\
\hline Trim/Sulfamethoxazole (58) & 69.8 & $47(81)$ & $11(18.9)$ \\
\hline Sulfonamides (67) & 80.7 & $53(79.1)$ & $14(20.9)$ \\
\hline Amoxicillin (55) & 66.2 & $42(76.3)$ & $13(23.6)$ \\
\hline Amoxicillin/clavulanic acid (36) & 43.3 & $25(69.4)$ & $11(30.5)$ \\
\hline Ticarcillin (27) & 32.5 & $18(66.6)$ & $9(33.3)$ \\
\hline Cefotaxime (3) & 3.6 & $2(66.6)$ & $1(33.3)$ \\
\hline Ceftazidime (2) & 2.4 & $1(50)$ & $1(50)$ \\
\hline Imipenem $(0)$ & 0 & na & na \\
\hline Nalidixic Acid (46) & 55.4 & $36(78.2)$ & $10(21.7)$ \\
\hline Ciprofloxacin (27) & 32.5 & $22(81.4)$ & $5(18.5)$ \\
\hline Chloramphenicol $(0)$ & 0 & na & na \\
\hline
\end{tabular}

na: not applicable.

TABLE 2: Resistance to different antimicrobial families according to the presence or absence of integrons.

\begin{tabular}{lcccc}
\hline Types of isolates & \multicolumn{4}{c}{$\begin{array}{c}\text { Number of isolates resistant to } \\
\text { the following number of } \\
\text { antimicrobial families: }\end{array}$} \\
& $<2^{\mathrm{a}}$ & 3 & 4 & $>5^{\mathrm{b}}$ \\
\hline Integron positive $(n=58)$ & 2 & 10 & 16 & 30 \\
Integron negative $(n=25)$ & 12 & 4 & 3 & 6 \\
\hline
\end{tabular}

${ }^{a}$ Integron-negative isolates were more frequently resistant to 2 or less families of antimicrobials than integron-positive isolates $(p<0.01)$.

${ }^{\mathrm{b}}$ Integron-positive isolates were more frequently resistant to 5 or more families of antimicrobials than integron-negative isolates $(p<0.001)$.

TABLE 3: Resistance genes detected by PCR assays in integronpositive and integron-negative $E$. coli isolates.

\begin{tabular}{|c|c|c|}
\hline \multirow{2}{*}{$\begin{array}{l}\text { Antimicrobial agent } \\
\text { (number of resistant } \\
\text { isolates) }\end{array}$} & \multicolumn{2}{|c|}{$\begin{array}{l}\text { Genes detected in isolates } \\
\text { (number of isolates): }\end{array}$} \\
\hline & $\begin{array}{l}\text { Integron positive } \\
(n)\end{array}$ & $\begin{array}{c}\text { Integron negative } \\
(n)\end{array}$ \\
\hline \multirow{7}{*}{ Sulfonamides (67) } & sul1 (18) & sul1(5) \\
\hline & sul2 (9) & sul2 (1) \\
\hline & sul3 (1) & sul3 (1) \\
\hline & sul1+sul2 (4) & \\
\hline & sull+sul3 (3) & \\
\hline & sul2+sul3 (1) & \\
\hline & sull+sul $2+$ sul $3(1)$ & \\
\hline \multirow{4}{*}{ Tetracycline (78) } & tetA (34) & tetA (19) \\
\hline & tetB $(6)$ & tetB $(2)$ \\
\hline & tetC (1) & tet $A+\operatorname{tet} B(1)$ \\
\hline & tet $A+\operatorname{tet} B(5)$ & \\
\hline
\end{tabular}

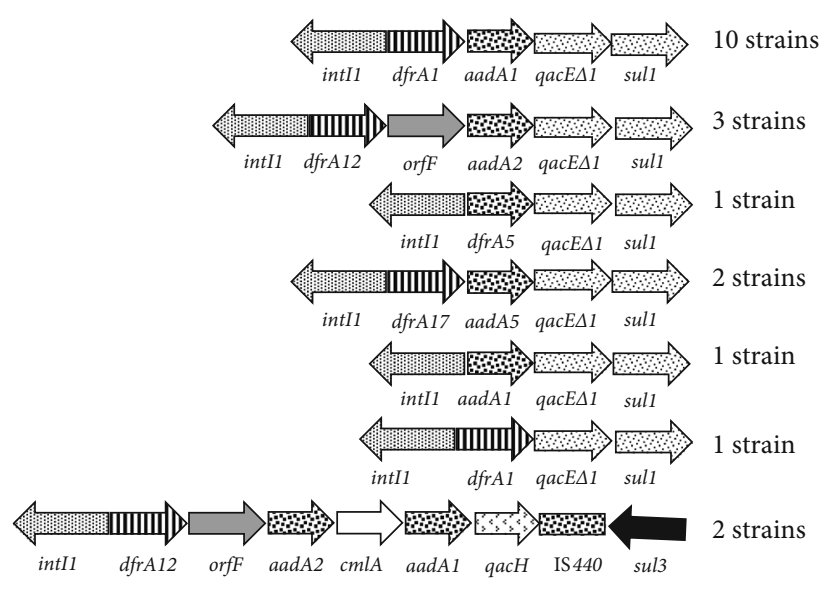

FIgURE 1: Gene cassette arrangements included in the class 1 integrons detected in 20 class 1 integron-positive $E$. coli strains. IntI1: gene encoding integrase of class 1 integron; dfr 1, dfrA5, $d f r A 12$, and $d f r A 17$ : genes encoding trimethoprim resistance; aadA1 and aadA2 and aadA5: genes encoding streptomycin/spectinomycin resistance; qacE $\Delta$ 1: gene encoding quaternary ammonium; sul1 and sul3 (in inversion direction): genes encoding sulfonamide resistance; cmlA: gene encoding chloramphenicol resistance. orfF: open reading frame of unknown function; IS440: insertion section 440 .

a high rate of tetracycline resistance is a general trait of avian E. coli in Tunisia [19]. Genes of tet type were detected in 65 isolates. tet $A$, tet $B$, and tet $C$ genes were observed in 59 (75.6\%), $14(17.9 \%)$, and one (1.2\%) tetracycline-resistant isolates, respectively. Absence of these genes in some of our resistant isolates might be due to the occurrence of nontested or unknown resistance genes. The predominance of tet $A$ and tet $B$ genes was also reported by other studies while the $t e t C$ gene is rarely reported [20-22]. 
Among 67 sulfonamide-resistant isolates, 44 isolates contained genes of sul type; resistance in the remaining isolates might be due to chromosomal mutation in dihydropteroatic synthetase (DHPS) [23]. sul1, sul2, and sul3 genes were detected in $31(46.2 \%), 16(23.8 \%)$, and $6(8.9 \%)$ sulfonamide-resistant isolates, respectively. In agreement with our results, the gene sul1 remains so far the most common gene followed by sul2 gene; however, sul3 is generally less frequent [24]. In contrast, in our previous study [25], the sul3 gene was the most prevalent one in avian E. coli isolates. A single ESBL-producing isolate was identified among our collection. Recently, worldwide, ESBL-producing E. coli isolates have been reported in livestock especially from poultry origin [26]. In Tunisia, the presence of ESBL-producing Enterobacteriales has been previously reported in E. coli from poultry, pets, dromedary, and meat of various animals [9-12]. In those studies, ESBL production was detected by using selective protocols, while Soufi et al. [19, 25] have not identified any ESBL-producing E. coli isolate from a collection of 164 isolates. Therefore, since our E. coli isolates were recovered and randomly selected from a nonselective medium (such as MacConkey agar+cefotaxime $[10,11]$ ), we were unable to identify high number of ESBLproducing isolates. The gene encoding the ESBL enzyme was identified as $b l a_{\mathrm{CTX}-\mathrm{M}-1}$, which is the most frequently reported ESBL gene in E. coli of animal origin in Tunisia and worldwide [27-29].

The role of plasmids in the dissemination of genes encoding antibiotic resistance is well documented. In addition, it appears that some plasmid types have a wide dissemination of power and are able to replicate in a wide host range [30]. Indeed, some plasmid types have been linked to the dissemination of genes encoding ESBL or fluoroquinolone resistance [30]. In our study, 29 (34.9\%) strains harbored at least one plasmid. Plasmids belonging to the incompatibility groups, IncFIB, IncF, IncK, and IncI1-I $\gamma$, were the most prevalent; moreover, it is worth noting the presence of multiple replicons in $22(26.5 \%)$ strains. These findings have been reported by other authors [30, 31]. Thus, the presence of multiple plasmids per strain represents an important genetic pool that might be used as a vector for antimicrobial resistance and/or virulence spreading within commensal intestinal E. coli isolates or other pathogenic genera such as Salmonella spp. [7, 27, 30-32]. Further genetic studies (hybridization or conjugation experiments) are needed to better understand the role of these plasmids. The remaining antimicrobial-resistant strains that did not harbor any of the investigated plasmid replicons likely harbored other nonsearched or novel replicons. Indeed, at least 27 plasmid incompatibility groups are recognized in Enterobacteriaceae [33]; however, we investigated only the 18 most common plasmid incompatibility groups. In addition, the used PCR-based replicon typing (PBRT) scheme targeting the replicons of the major plasmid families occurring in Enterobacteriaceae has several limitations and can fail to identify divergent or novel replicons [33]. It is also plausible that all those strains or at least part of them are plasmid free and that their genes encoding antimicrobial resistance are chromosomally located.
Integrons of class 1 were found in 57 isolates while class 2 only in two isolates; our results were in agreement with other works which showed the dominance of class 1 integron in E. coli isolates of animal and human origins [19, 25]. Class 1 integron is a dynamic genetic system encoding a functional integrase protein enabling integration and expression of several gene cassettes that are nonreplicative mobile elements, in the bacterial genome [5, 13, 14]. This genetic trait explains in part the high dominance of class 1 integrons in Enterobacteriaceae, particularly in resistant isolates and in a rich antimicrobial environment $[13,14,19]$. Classic class 1 integrons are mainly characterized by a $3^{\prime}$ conserved region containing qacE $\Delta$ (encoding resistance to quaternary ammonium) and sul1 (encoding resistance to sulfonamides) genes; however, in our isolates only 22 (38.5\%) out of the 57 class 1 integron-positive isolates harbored this sequence. This finding is in agreement with other studies reporting the absence of this region in class 1 integrons $[19,25,32]$. In a genetic point of view, it is plausible that crucial genetic rearrangements in class 1 integron happened. Indeed, this region was replaced by a 'transposonlike' structure, a qacH-IS440-sul3, which could facilitate the dissemination of class 1 integron by a mechanism of transposition [34]. Owing to many financial limitations, we sequenced the variable regions of only 21 strains harboring the class 1 and 2 integrons; among them, one contained both types of integrons. In 20 class 1-positive isolates, the VR showed the presence of seven arrangements of gene cassettes. We found that the gene cassette array $d f r A 1$-aadA1 was the most frequently detected. Furthermore, two isolates harbored a long gene cassette array with unclassic $3^{\prime} \mathrm{CS}$ : dfrA12-orfF-aadA2-cmlA1-aadA1-qacH-IS440-sul3. This structure, known as sul3-associated integron type I, was also reported by other authors [25, 35]. This phenomenon of substitution of qacE $\Delta$-sul1 by qacH-IS440-sul3 might be for perfection rather than change of function. Indeed, the inserted $q a c H$ and sul3 genes code for the same functions as qacE $\Delta 1$ (resistance the quaternary ammonium) and sull (resistance to sulfonamides) genes, respectively. Genetically, this could be explained by the continuous use of the ammonium-quaternary and sulfonamides until current days in avian industries in Tunisia and worldwide [36]. A unique gene cassette array $d f r A 1$-sat1-aadA1 was identified in the variable region of class 2 integrons of two isolates. This structure is common in all class 2 integrons identified worldwide [32].

\section{Conclusion}

Taken together, these findings highlight the importance of intestinal avian $E$. coli as a reservoir of antibiotic resistance that is certainly linked to the excessive use of antibiotic in avian husbandry in Tunisia. This dramatical situation is not specific to Tunisia. Therefore, this is worrisome for global human health, especially with the increasing consumption of poultry meat in Tunisia and in other parts of the world owing to its relatively lower cost comparing to red meat. 


\section{Data Availability}

The statistical data used to support the findings of this study are available from the corresponding author upon request.

\section{Conflicts of Interest}

The authors declare that there is no conflict of interest regarding the publication of this paper.

\section{Authors' Contributions}

Study concept and drafting of the manuscript were done by Kilani H, Abbassi MS, Ben Chehida N, and Boutiba-Ben boubaker I. Acquisition, analysis, and interpretation of data were performed by Kilani H, Abid I, and Abbassi MS. Drafting of the manuscript was done Kilani H, Abid I, Hynds P, Abbassi MS, and Saenz, Y. Critical revision of the manuscript for important intellectual content was conducted by Ben Chehida $\mathrm{N}$ and Boutiba-Ben boubaker I.

\section{Acknowledgments}

Kilani hajer has a fellowship from the Tunisian Ministry of Higher Education and Scientific Research.

\section{References}

[1] C. J. Maynard, J. M. Fairbrother, S. Bekal et al., "Antimicrobial resistance genes in EnterotoxigenicEscherichia coliO149:K91 isolates obtained over a 23-year period from pigs," Antimicrobial Agents and Chemotherapy, vol. 47, no. 10, pp. 3214-3221, 2003.

[2] T. M. Wassenaar and P. Silley, "Antimicrobial resistance in zoonotic bacteria: lessons learned from host-specific pathogens," Animal Health Research Reviews, vol. 9, pp. 177-186, 2005.

[3] A. Smet, A. Martel, D. Persoons et al., "Broad-spectrum $\beta$-lactamases amongEnterobacteriaceaeof animal origin: molecular aspects, mobility and impact on public health," FEMS Microbiology Reviews, vol. 34, no. 3, pp. 295-316, 2010.

[4] F. Baquero, "From pieces to patterns: evolutionary engineering in bacterial pathogens," Nature Reviews. Microbiology, vol. 2, no. 6, pp. 510-518, 2004.

[5] S. R. Partridge, G. D. Recchia, H. W. Stokes, and R. M. Hall, "Family of class 1 integrons related to In4 from Tn1696," Antimicrobial Agents and Chemotherapy, vol. 45, no. 11, pp. 30143020, 2001.

[6] K. E. Preston, E. M. Graffunder, A. M. Evans, and R. A. Venezia, "Survey of plasmid-associated genetic markers inEnterobacteriaceaewith reduced susceptibilities to cephalosporins," Antimicrobial Agents and Chemotherapy, vol. 47, no. 7, pp. 2179-2185, 2003.

[7] L. Villa, C. Pezzella, F. Tosini, P. Visca, A. Petrucca, and A. Carattoli, "Multiple-antibiotic resistance mediated by structurally related IncL/M plasmids carrying an extended-spectrum $\beta$-Lactamase gene and a class 1 integron," Antimicrobial Agents and Chemotherapy, vol. 44, no. 10, pp. 2911-2914, 2000.

[8] M. Wang, J. H. Tran, G. A. Jacoby, Y. Zhang, F. Wang, and D. C. Hooper, "Plasmid-mediated quinolone resistance in clin- ical isolates ofEscherichia colifrom Shanghai, China," Antimicrobial Agents and Chemotherapy, vol. 47, no. 7, pp. 22422248, 2003.

[9] R. Ben Sallem, K. Ben Slama, Y. Sáenz et al., "Prevalence and characterization of extended-spectrum beta-lactamase (ESBL) - and CMY-2-ProducingEscherichia coliIsolates from healthy food-producing animals in Tunisia," Foodborne Pathogens and Disease, vol. 9, no. 12, pp. 1137-1142, 2012.

[10] R. Grami, W. Mansour, S. Dahmen et al., "The bla $a_{\text {CтX-M-1 }}$ IncI1/ST3 plasmid is dominant in chickens and pets in Tunisia," The Journal of Antimicrobial Chemotherapy, vol. 68, no. 12, pp. 2950-2952, 2013.

[11] B. Mnif, S. Ktari, F. M. Rhimi, and A. Hammami, "Extensive dissemination of CTX-M-1- and CMY-2-producingEscherichia coliin poultry farms in Tunisia," Letters in Applied Microbiology, vol. 55, no. 6, pp. 407-413, 2012.

[12] A. Jouini, L. Vinue, K. B. Slama et al., "Characterization of CTX-M and SHV extended-spectrum-lactamases and associated resistance genes in Escherichia coli strains of food samples in Tunisia," The Journal of Antimicrobial Chemotherapy, vol. 60, no. 5, pp. 1137-1141, 2007.

[13] A. Carotoli, "Importance of integrons in the diffusion of resistance," Veterinary Research, vol. 32, no. 3/4, pp. 243-259, 2001.

[14] D. A. Rowe-Magnus and D. Mazel, "The role of integrons in antibiotic resistance gene capture," International Journal of Medical Microbiology, vol. 292, no. 2, pp. 115-125, 2002.

[15] CLSI, Performance Standards for Antimicrobial Susceptibility Testing, Clinical and Laboratory Standards Institute, Wayne, PA, USA, 27th edition, 2017.

[16] A. P. Magiorakos, A. Srinivasan, R. B. Carey et al., "Multidrugresistant, extensively drug-resistant and pandrug-resistant bacteria: an international expert proposal for interim standard definitions for acquired resistance," Clinical Microbiology and Infection, vol. 18, no. 3, pp. 268-281, 2012.

[17] A. Carattoli, A. Bertini, L. Villa, V. Falbo, K. L. Hopkins, and E. J. Threlfall, "Identification of plasmids by PCR-based replicon typing," Journal of Microbiological Methods, vol. 63, no. 3, pp. 219-228, 2005

[18] Y. Sáenz, L. Vinué, E. Ruiz et al., "Class 1 integrons lacking qacE $\Delta 1$ and sul1 genes in Escherichia coli isolates of food, animal and human origins," Veterinary Microbiology, vol. 144, no. 3-4, pp. 493-497, 2010.

[19] L. Soufi, M. S. Abbassi, Y. Sáenz et al., "Prevalence and diversity of integrons and associated resistance genes inEscherichia coliIsolates from poultry meat in Tunisia," Foodborne Pathogens and Disease, vol. 6, no. 9, pp. 10671073, 2009.

[20] T. Zhang, C. G. Wang, J. C. Lv, R. S. Wang, and X. H. Zhong, "Survey on tetracycline resistance and antibiotic-resistant genotype of avian Escherichia coli in North China," Poultry Science, vol. 91, no. 11, pp. 2774-2777, 2012.

[21] H. J. Koo and G. J. Woo, "Distribution and transferability of tetracycline resistance determinants in Escherichia coli isolated from meat and meat products," International Journal of Food Microbiology, vol. 145, no. 2-3, pp. 407-413, 2011.

[22] M. Sunde and M. Norström, "The prevalence of, associations between and conjugal transfer of antibiotic resistance genes in Escherichia coli isolated from Norwegian meat and meat products," The Journal of Antimicrobial Chemotherapy, vol. 58, no. 4, pp. 741-747, 2006. 
[23] O. Sköld, "Resistance to trimethoprim and sulfonamides," Veterinary Research, vol. 32, no. 3/4, pp. 261-273, 2001.

[24] M. Trobos, L. Jakobsen, K. E. Olsen et al., "Prevalence of sulphonamide resistance and class 1 integron genes in Escherichia coli isolates obtained from broilers, broiler meat, healthy humans and urinary infections in Denmark," International Journal of Antimicrobial Agents, vol. 32, no. 4, pp. 367-369, 2008.

[25] L. Soufi, Y. Sáenz, L. Vinué et al., "Escherichia coli of poultry food origin as reservoir of sulphonamide resistance genes and integrons," International Journal of Food Microbiology, vol. 144, no. 3, pp. 497-502, 2011.

[26] D. Trott, " $\beta$-lactam resistance in Gram-negative pathogens isolated from animals," Current Pharmaceutical Design, vol. 19, no. 2, pp. 239-249, 2013.

[27] R. Cantón, J. M. González-Alba, and J. C. Galán, "CTX-M enzymes: origin and diffusion," Frontiers in Microbiology, vol. 3, p. 110, 2012.

[28] B. Hassen, B. Saloua, M. S. Abbassi et al., " $m c r-1$ encoding colistin resistance in CTX-M-1/CTX-M-15- producing Escherichia coli isolates of bovine and caprine origins in Tunisia. First report of CTX-M-15-ST394/D E. coli from goats," Comparative Immunology, Microbiology and Infectious Diseases, vol. 67, article 101366, 2019.

[29] S. Sghaier, M. S. Abbassi, A. Pascual et al., "Extended-spectrum $\beta$-lactamase-producing Enterobacteriaceae from animal origin and wastewater in Tunisia: first detection of O25b-B2 ${ }_{3}$-CTXM-27-ST131 Escherichia coli and CTX-M-15/OXA-204-producing Citrobacter freundii from wastewater," Journal of Global Antimicrobial Resistance, vol. 17, pp. 189-194, 2019.

[30] A. Carattoli, "Plasmids in Gram negatives: molecular typing of resistance plasmids," International Journal of Medical Microbiology, vol. 301, no. 8, pp. 654-658, 2011.

[31] N. Rayamajhi, S. B. Cha, S. W. Shin, B. Y. Jung, S. K. Lim, and H. S. Yoo, "Plasmid typing and resistance profiling of Escherichia fergusonii and other Enterobacteriaceae isolates from South Korean farm animals," Applied and Environmental Microbiology, vol. 77, no. 9, pp. 3163-3166, 2011.

[32] K. F. Chah, I. C. Agbo, D. C. Eze, S. Somalo, V. Estepa, and C. Torres, "Antimicrobial resistance, integrons and plasmid replicon typing in multiresistant clinical Escherichia coli strains from Enugu state, Nigeria," Journal of Basic Microbiology, vol. 50, no. S1, pp. S18-S24, 2010.

[33] A. Carattoli, "Resistance plasmid families inEnterobacteriaceae," Antimicrobial Agents and Chemotherapy, vol. 53, no. 6, pp. 2227-2238, 2009.

[34] P. Antunes, J. Machado, and L. Peixe, "Dissemination ofsul3Containing elements linked to class 1 integrons with an unusual $3^{i}$ conserved sequence region amongSalmonellaIsolates," Antimicrobial Agents and Chemotherapy, vol. 51, no. 4, pp. 1545-1548, 2007.

[35] M. Sunde, H. Solheim, and J. S. Slettemeås, "Genetic linkage between class 1 integrons with the $d f r A 12$-orfF- aadA2 cassette array and sul3 in Escherichia coli," Veterinary Microbiology, vol. 130, no. 3-4, pp. 422-425, 2008.

[36] N. Roth, A. Käsbohrer, S. Mayrhofer, U. Zitz, C. Hofacre, and K. J. Domig, "The application of antibiotics in broiler production and the resulting antibiotic resistance in Escherichia coli: A global overview," Poultry Science, vol. 98, no. 4, pp. 17911804, 2019. 